\title{
Photodynamic therapy: Esophagus
}

\author{
L Gossner MD PhD
}

L Gossner. Photodynamic therapy: Esophagus. Can J Gastroenterol 2002;16(9):642-644.

Photodynamic therapy (PDT) is a minimally invasive, organ-preserving therapeutic modality, involving three separate components - light, oxygen and a photosensitizing drug. The principles of PDT are described, and the indications for its use are reviewed. Although a widespread clinical application for PDT has not yet emerged, PDT may establish itself as an endoscopic procedure with few or no side effects in the treatment of Barrett's esophagus (high-grade dysplasia and early carcinoma) and, in selected cases, for the treatment of early squamous cell carcinoma.

\section{Thérapie photodynamique de l'œsophage}

RÉSUMÉ : La thérapie photodynamique (TPD) est une forme de traitement peu effractive, qui permet de sauvegarder l'organe et qui fait appel à trois éléments : la lumière, l'oxygène et une substance photosensibilisante. Il sera question dans le présent article des principes de la TPD et de ses indications. Même si le traitement ne donne pas lieu encore à une application clinique généralisée, il pourrait s'avérer une intervention endoscopique produisant peu ou pas d'effets indésirables dans le traitement de l'œsophage de Barrett (dysplasie de haut grade de malignité ou début de carcinome) et, dans certains cas, dans le traitement du carcinome spino-cellulaire au stade initial.

Key Words: Barrett's esophagus; Esophagus; Photodynamic therapy; Squamous cell carcinoma

$\mathrm{T}$ he idea of treating tumours with photosensitizers dates back to the early 1900s. However, reports concerning intraluminal photodynamic therapy (PDT) in the gastrointestinal tract first appeared in the late 1980s, and were greeted with both enthusiasm and controversy. In that respect, little has changed, not because PDT has been outdated, its technical potential has been fully exhausted or it has been superseded by more modern procedures, but because PDT is still going through a dynamic process of development, improvement and standardization.

\section{PHOTODYNAMIC PRINCIPLE}

PDT is a minimally invasive, organ-preserving therapeutic modality, involving three separate components - light, oxygen and a photosensitizing drug. PDT exploits the physical phenomenon that light is able to activate photosensitizing compounds that are incorporated by tissue. Light energy absorbed by the photosensitizer is transferred in several steps, primarily to oxygen within the tissue, leading to tumour destruction through oxidation processes. Laser light with a specific wavelength within the relative maximum of

HSK, Klinikum der Landeshauptstadt Wiesbaden, Wiesbaden, Germany

Correspondence and reprints: Dr L Gossner, Innere Medizin 11, HSK, Klinikum der Landeshauptstadt Wiesbade GmbH,

Ludwig-Erhard-Strasse 100, D-65199 Wiesbaden, Germany. Telephone +49(0)611-432420, fax +49(0)611-432418

Received for publication July 17, 2001. Accepted July 17, 2001 
the absorption band of the applied photosensitizer is delivered endoscopically through a flexible fibre into the gastrointestinal tract, and is then used for topical irradiation of the sensitized dysplastic or malignant tissue.

\section{PALLIATIVE TREATMENT}

Palliative treatment of stenotic tumours of the esophagus does not provide any hopeful prospects for widespread use of PDT. Although a multicentre American study of obstructing esophageal cancer showed that fewer treatment sessions were required with PDT than with Nd:YAG laser therapy, and that PDT was associated with a lower perforation rate, the economic arguments are not convincing in view of the high cost of PDT and the short life expectancy in this group of patients (1). The American health authorities have approved PDT exclusively for palliation, but in clinical reality, there are simpler thermodestruction procedures. Particularly in the esophagus, well established techniques using self-expanding metal endoprostheses are available for simpler and more effective palliation.

\section{Barrett's esophagus}

\section{CURATIVE TREATMENT}

The most frequent indication for PDT in the future may be Barrett's esophagus. However, PDT of any type is in competition with the various methods of thermoablation and endoscopic mucosal resection (EMR). The incidence of diagnosis of Barrett's esophagus has increased rapidly in recent years. There is currently a broad awareness of the metaplasia-dysplasia-carcinoma sequence, which in part explains the increasing rate of diagnosis. In a more detailed discussion, it would be useful to distinguish between Barrett's metaplasia with or without dysplasia, and severe dysplasia or early Barrett's carcinoma. Local endoscopic therapy for Barrett's esophagus with or without mild dysplasia should be performed under the condition that the method allows complete ablation of the undesirable epithelium and complete restitution of orthotopic epithelium. The existing data do not allow firm conclusions to be drawn. However, data on the use of PDT in the treatment of Barrett's epithelium seem to be slightly better than those for thermoablation (2). In addition, the spot effects of thermal procedures - either laser coagulation or thermocoagulation - produce varying ablation depths, and frequently cause tissue destruction and affect the submucosa. By contrast, PDT with 5-aminolevulinic acid (ALA) is limited in its destructive effects on the mucosa, as has been adequately shown in animal experiments. In this respect, ALA-PDT has a clear advantage over thermocoagulation procedures. In addition, suitable light applicators can be used to achieve homogeneous and circumferential irradiation in a single session, over a length of up to $8 \mathrm{~cm}$ (3). In summary, it appears that ALA-PDT treatment of Barrett's mucosa with or without mild dysplasia has basic advantages over the alternative procedures, although adequate clinical confirmation is lacking. In addition, whether ablation techniques, in general, provide an economically defensible form of carcinoma prevention has not been adequately confirmed.

Although the case numbers are smaller, the question of how to deal with Barrett's epithelium and high-grade dysplasia or early carcinoma is of much greater clinical relevance. The gold standard is undoubtedly still radical surgery, with partial gastric and esophageal resection. However, careful study of the published surgical data shows that there are good arguments for local therapy. The morbidity and mortality rates associated with radical surgery are high - amounting to between $30 \%$ and $50 \%$, or $3 \%$ and $5 \%$ in patients with high-grade dysplasia or early carcinoma associated with Barrett's esophagus, respectively. The available surgical and pathoanatomical data indicate that the risk of lymph node metastasis in high-grade dysplasia and in mucosal early carcinoma is almost zero. In any case, the risk is lower than that with surgery. In choosing a local treatment procedure, EMR is undoubtedly the first option. However, EMR can only be used if the malignant lesions can be clearly located. In addition, the resection cannot exceed a certain size, and in multifocal conditions, EMR is not yet a suitable form of primary therapy (4). This suggests that there is one potential indication for PDT. When malignancy or severe dysplasia has been shown on biopsy but macroscopic identification is unclear, and in cases of long Barrett's segments with advanced histological changes, PDT should be considered as a primary form of local treatment.

With the usual form of PDT, strictures occur in up to one-half of patients, but these are easy to treat endoscopically. In a study by Overholt and Panjehpour (5), this relatively aggressive form of treatment was followed by complete remission in all patients, which was confirmed during a follow-up period of up to five years. Using the 'milder' form of ALA-PDT, which is limited to selective destruction of the mucosa, Barr's group (6) and our own group (2) achieved long-term complete remission in all cases of high-grade dysplasia. However, long term remission was seen in only around $75 \%$ of patients who already had early carcinoma (7). When the mucosa has thickened by more than $2 \mathrm{~mm}$, ie, when mucosal changes are already visible macroscopically, ALA-PDT is very likely to be inadequate, and a more intensive form of PDT should be used instead - for example, with mesa-tetrahydroxyphenyl-chlor as the photosensitizer (8). The data on PDT in severe dysplasia and early carcinoma in Barrett's esophagus are very promising, but due to the small numbers of patients overall and the very short follow-up period, a conclusive assessment of the value of the method is not yet possible.

\section{EARLY ESOPHAGEAL CANCER}

There have been very few reports on the use of PDT in the treatment of early squamous cell carcinoma in the esophagus, at least from the Western hemisphere. When ALA is used as the photosensitizer, all of the patients with highgrade dysplasia who were treated (9) complete remission, but only about one-half of those with confirmed early carcinoma had remissions. No significant side effects of the 
treatment were observed (9). By contrast, the results of PDT with mesa-tetrahydroxyphenyl-chlor of one group (10) were better with regard to complete remission, although at the expense of increased morbidity. In summary, PDT may be of significance for the treatment of highrisk patients with early squamous cell carcinoma, because in comparison with radical surgery or aggressive chemoradiotherapy, PDT is a form of minimally invasive treatment. However, the search for optimal irradiation conditions is not yet complete.

\section{REFERENCES}

1. Lightdale CJ, Heier SK, Marcon NE, et al. Photodynamic therapy with porfimer sodium versus thermal ablation therapy with $\mathrm{Nd}: Y A G$ laser for palliation of esophageal cancer: a multicenter randomized trial. Gastrointest Endosc 1995;42:507-12.

2. Gossner L, May A, Stolte M, Seitz G, Ell C. KTP-laser destruction of dysplasia and early cancer in columnar-lined Barrett's esophagus. Gastrointest Endosc 1999;49:8-12.

3. Gossner L, Sroka R, Ell C. A new long-range through-the-scope balloon applicator for photodynamic therapy in the esophagus and cardia. Endoscopy 1999;31:370-6.

4. Ell C, May A, Gossner L, et al. Endoscopic mucosal resection of early cancer and high-grade dysplasia in Barrett's esophagus. Gastroenterology 2000;118:670-7.

5. Overholt BF, Panjehpour M. Photodynamic therapy for Barrett's esophagus: clinical update. Am J Gastroenterol 1996;91:1719-22.

\section{CONCLUSIONS}

PDT is a fascinating concept that will continue to occupy many research groups around the world in the coming years. Although a widespread clinical application for the method has not yet emerged, there are good prospects that PDT will be able to establish itself at major gastroenterological centres as an endoscopic procedure with few or no side effects in the treatment of Barrett's esophagus (high-grade dysplasia and early carcinoma) and, in selected cases, also for the treatment of early squamous cell carcinoma.

6. Barr H, Shepherd NA, Dix A, Roberts DJ, Tan WC, Krasner N. Eradication of high-grade dysplasia in columnar-lined (Barrett's) oesophagus by photodynamic therapy with endogenously generated protoporphyrin IX. Lancet 1996;348:584-5.

7. Gossner L, Stolte M, Sroka R, et al. Photodynamic ablation of highgrade dysplasia and early cancer in Barrett's esophagus by means of 5-aminolevulinic acid. Gastroenterology 1998;114:448-55.

8. Ell C, Gossner L, May A, et al. Photodynamic therapy of early gastric cancer with mTHPC. Gut 1998;43:345-9.

9. Gossner L, May A, Sroka R, Stolte M, Hahn EG, Ell C. Destruction of high-grade dysplasia and early carcinoma of the esophagus after oral administration of 5-aminolevulinic acid. Cancer 1999;86:1921-8.

10. Savary JF, Monnier P, Fontolliet C, et al. Photodynamic therapy for early squamous cell carcinomas of the esophagus, bronchi, and mouth with m-tetra (hydroxyphenyl) chlorin. Arch Otolaryngol Head Neck Surg 1997;123:162-8. 


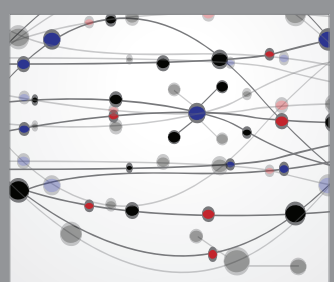

The Scientific World Journal
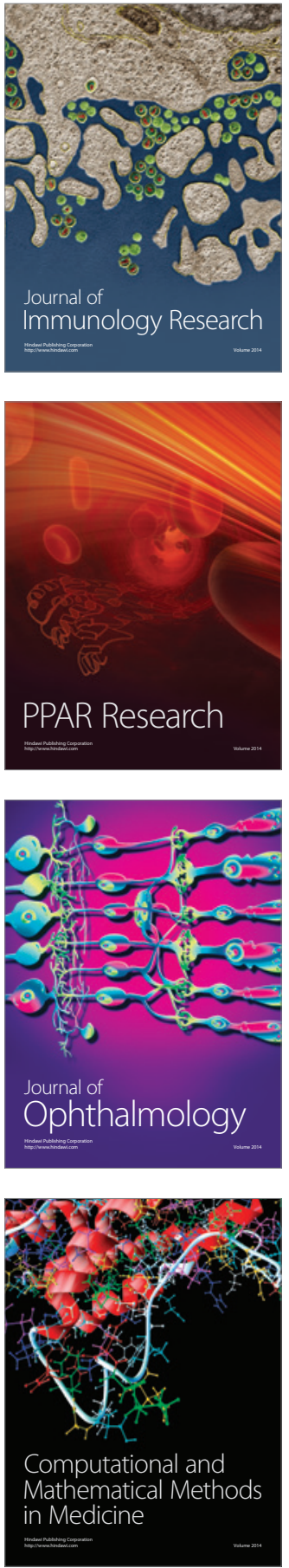

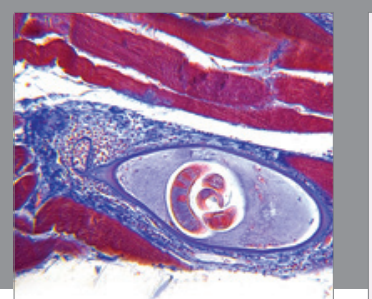

Gastroenterology Research and Practice

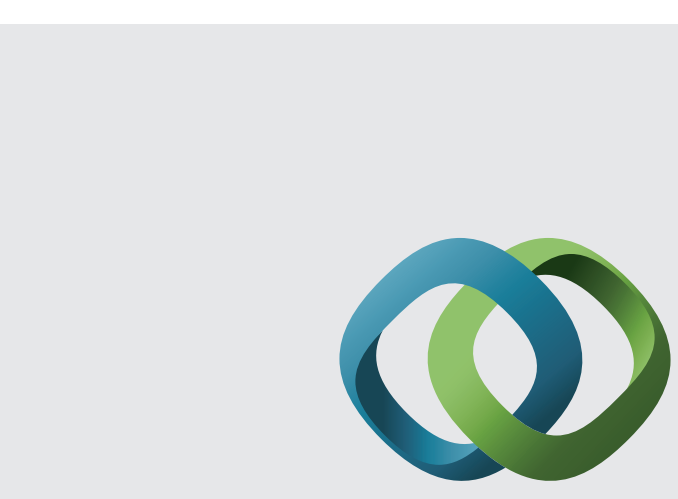

\section{Hindawi}

Submit your manuscripts at

http://www.hindawi.com
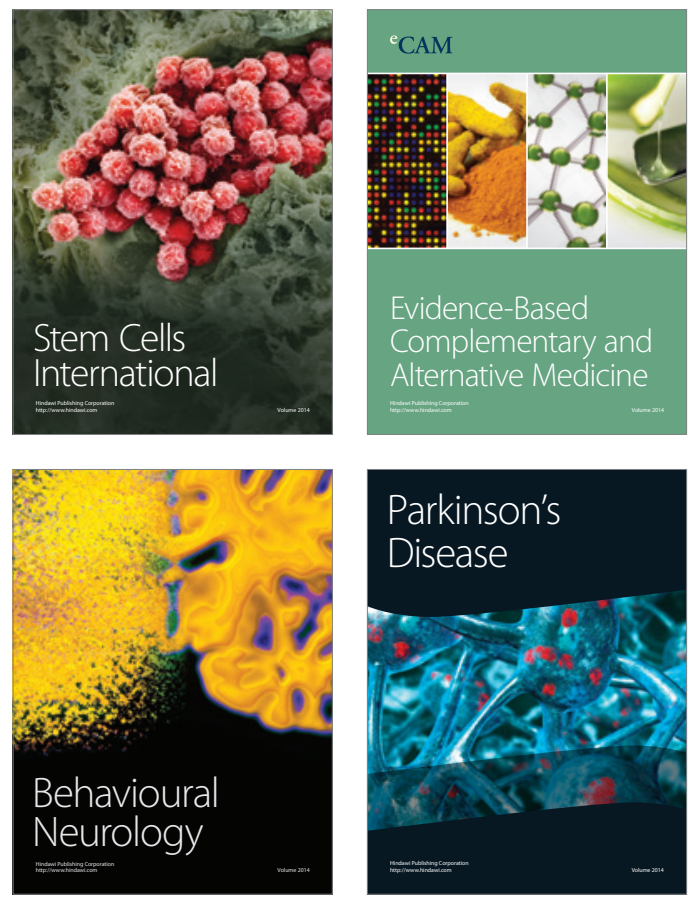
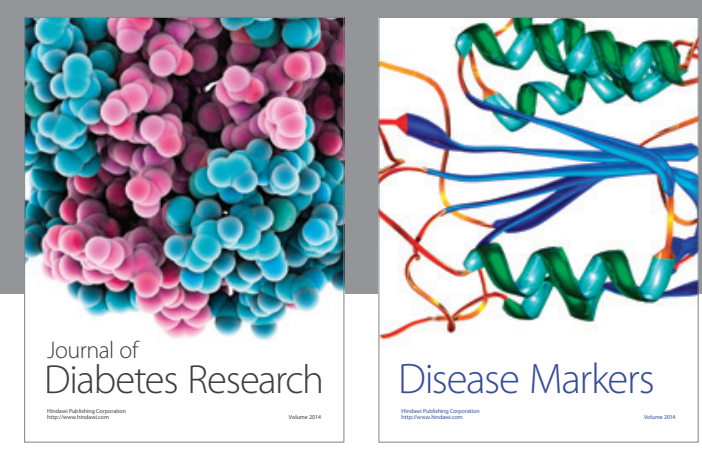

Disease Markers
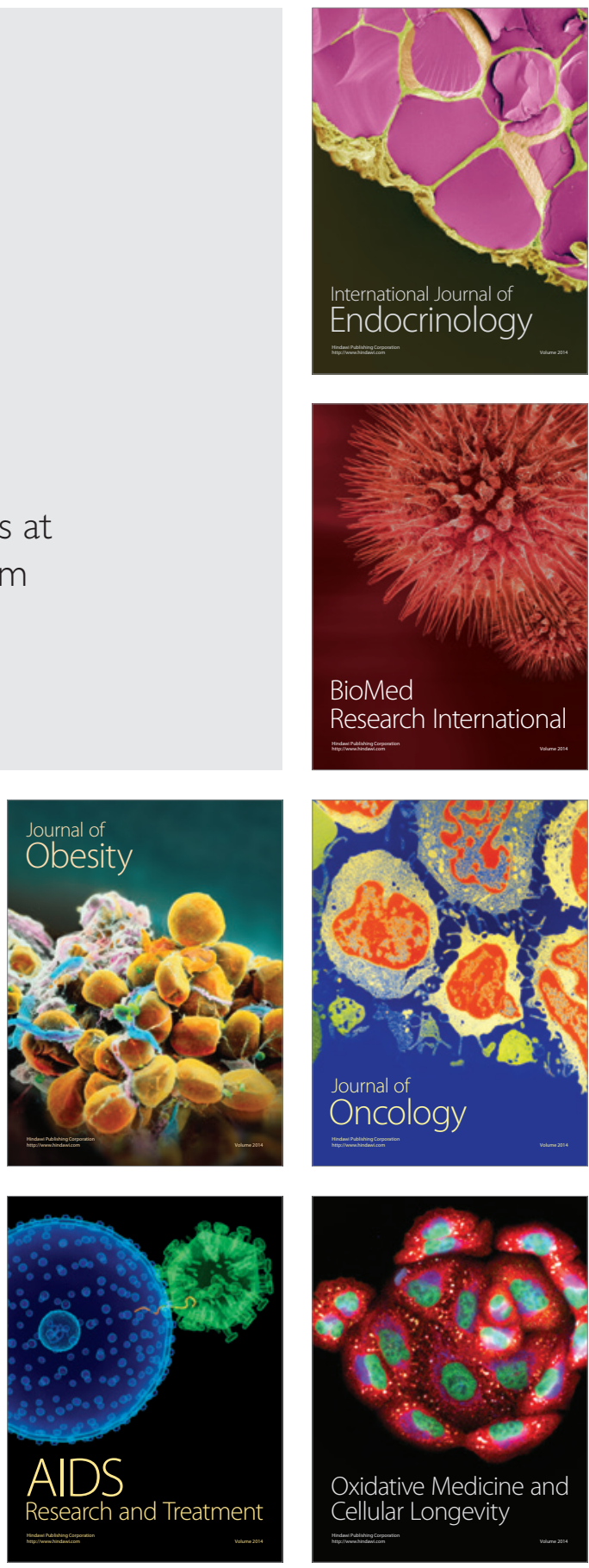